\title{
Correction to: The semantic plights of the ante-rem structuralist
}

\section{Bahram Assadian ${ }^{1}$}

\section{Correction to: Philos Stud \\ DOI https://doi.org/10.1007/s11098-017-1001-7}

In the original publication of the article, footnote 17 was incorrectly published. The corrected footnote is given below.

Footnote 17:

Hellman (2001, pp. 193-6), Button and Walsh (2016, §2.3), and Ketland (ms.) have briefly discussed the permutation argument in the context of ante-rem structuralism. I will expand the argument and the structuralist's possible responses. Hellman's paper is the original source of the permutation argument in this context.

The original article can be found online at https://doi.org/10.1007/s11098-017-1001-7.

Bahram Assadian

bassad01@mail.bbk.ac.uk

1 Department of Philosophy, Birkbeck College, Malet Street, London WC1E 7HX, UK 